\title{
How Thumbelina Knows
}

\author{
Giorgio De Michelis \\ Department of Informatics Systems and Communication (DISCo), University of Milano-Bicocca, \\ 20126 Milano, Italy; gdemich@disco.unimib.it \\ Academic Editor: Remo Pareschi \\ Received: 3 August 2016; Accepted: 31 October 2016; Published: 16 November 2016
}

\begin{abstract}
In this paper, I take the book by Michel Serres, "Thumbelina", as an occasion for reflection on the conceptual basis of knowledge management, as was built by Nonaka and co-workers. The direct access to knowledge that Thumbelina practices together with her peers is, in fact, for me, and is a good observation point to bring Nonaka's reflection further towards the discovery of a new understanding of knowledge and knowing processes. If the digital revolution is the third step, after writing and printing, regarding the soft changes in the relations between human beings and knowledge, then it highlights the urgent problem of deepening our understanding of what knowledge and intelligence are, changing our practices at the educational level, and designing new digital tools to support our knowledge management processes.
\end{abstract}

Keywords: knowledge management; tacit knowledge; explicit knowledge

\section{Introduction}

In 2014, Rowman and Littlefield International published the English translation of "Petite Poucette" by Daniel W. Smith, with the title "Thumbelina" [1] a small, beautiful book written by Michel Serres, which appeared in France in 2012. Michel Serres is an 86-year-old French philosopher, who spent long periods of his life in the United States, teaching the history of science, since 1984, at Stanford University. "Thumbelina" contains his answer to a simple question, which he poses at the very beginning: "Before teaching to anyone we should at least know who our students are. Who, today, is enrolling in our schools, colleges and universities?" ([1], p. 1). Thumbelina is, therefore, the paradigmatic representative of young people in the third millennium, those who are today called Millennials. Serres observes her with a warm and curious gaze and shows us how she is a new type of human being, mostly because of her growing up in a society where the digital revolution has happened. Serres claims that the digital revolution can be better characterized as another step, after writing and printing, radically changing how human beings relate with knowledge, rather than as an innovation in the hard technologies after the industrial revolution. It is, therefore, natural that what characterizes Thumbelina is the fact that she is the first human being accessing knowledge without any mediator. It, thus, makes sense to ask if Thumbelina offers us a new viewpoint for discussing how human beings create, circulate, and share knowledge (i.e., all the practices collected under the heading 'knowledge management'). We are interested in the conceptual foundations of knowledge management, disregarding its applications within organizations, as well as the methods and systems characterizing those applications. For the sake of efficiency, we will not propose a complete survey of the ideas driving the debate within knowledge management literature; rather, we will take Nonaka's work almost exclusively as a reference point [2-4] since its relevance is widely recognized in the field and it has solid theoretical grounds. We will see that what Michel Serres sees in Thumbelina allows us to suppose that the relationship between the individual and collective knowledge, implicit in the knowledge spiral of Nonaka and Takeuchi [4], is not only characterized by their mutual feeding through internalization and externalization, but is such that people can create new knowledge, only in the context of sharing knowledge with the people they are interacting with. 
However, this is what the paper is about, and we cannot anticipate how our discourse will develop without making it generic and vague.

The paper will bring its readers on a trip in which, after a short survey of the most relevant points in knowledge management theories, they are presented with Thumbelina through a summary of Serres' book [1]. Thereafter, starting from the relationship between Thumbelina and knowledge, we will discuss how well-established concepts in knowledge creation and learning are remixed in the digital age, so that we can better see how Thumbelina, and any other person, knows. The concluding remarks will discuss some implications of the findings and suggestions we obtain on this trip.

\section{Knowledge Management}

Knowledge management has emerged in the last thirty years as a multidisciplinary field of research, where scholars and practitioners discuss the theoretical and practical issues raised by human practices meant to preserve and update the knowledge of an organization and/or of a community. Knowledge management has been studied, experimented with, and practiced, while paying attention to its human (psychological, social, and organizational) and technological aspects. With respect to technology, several systems have also been developed to support it and its evaluation in action. However, the core of the research on knowledge management has been highly theoretical, focusing on questions like: What is the knowledge we aim to manage? What does it mean to share it? What role does technology play in knowledge management?

As mentioned in the Introduction, Nonaka and his co-workers (I quote, among them, Hirotaka Takeuchi, Noboru Konno, and Georg Von Krogh) played a crucial role at this level. Nonaka became a reference author for knowledge management after his studies on the differences between Western and Japanese companies. From the 1990s to today, these studies drove him to look at the value of companies, i.e., at their potential for innovation, where the capability to create new knowledge plays a major role [2-4]. In order to deepen their understanding of the mechanisms through which organizations manage knowledge, Nonaka and co-workers distinguish two types of knowledge: Tacit and explicit knowledge. Tacit knowledge (inspired by the studies of Karl Polanyi [5] in the mid-twentieth century) characterizes what people are able to do, their know-how, while explicit knowledge is what is contained in books, documents, databases, etc. The creation of new knowledge is not unrelated to previous knowledge; rather, it is obtained by transforming existing knowledge. Since there are two types of knowledge, there are four transformation modes: From tacit to tacit (socialization), from tacit to explicit (externalization), from explicit to explicit (combination) and, finally, from explicit to tacit (internalization). Nonaka underlines that all four transformation modes are needed to create new knowledge with continuity: Good companies are able to keep the knowledge spiral (Figure 1) alive, creating a constant flow of new knowledge.

The spiral is the never-ending process of letting knowledge flow within the organization: Through socialization, newly created ability to perform is shared; through internalization, external knowledge is appropriated; and through externalization, know-how is made available to the external world as explicit knowledge that can be updated through combination. It is interesting that the knowledge spiral generates two horizontal movements as well: While internalization concentrates knowledge from large communities sharing access to explicit knowledge into small groups of strictly interacting people, externalization does the opposite, making the knowledge created within small groups of interacting people accessible to larger communities with access to the repository where related documents are stored.

Nonaka's contribution has been widely appreciated because it has given a solid theoretical basis to the shared persuasion that knowledge management cannot be reduced to making the knowledge possessed by its members available in the data and document repositories of the organization, putting, I hope, a final word on the false expectation that organizations can store the knowledge created by their members into documents and databases. Tacit and explicit knowledge are mutually related, but they are not the same; rather, they are intrinsically diverse. 


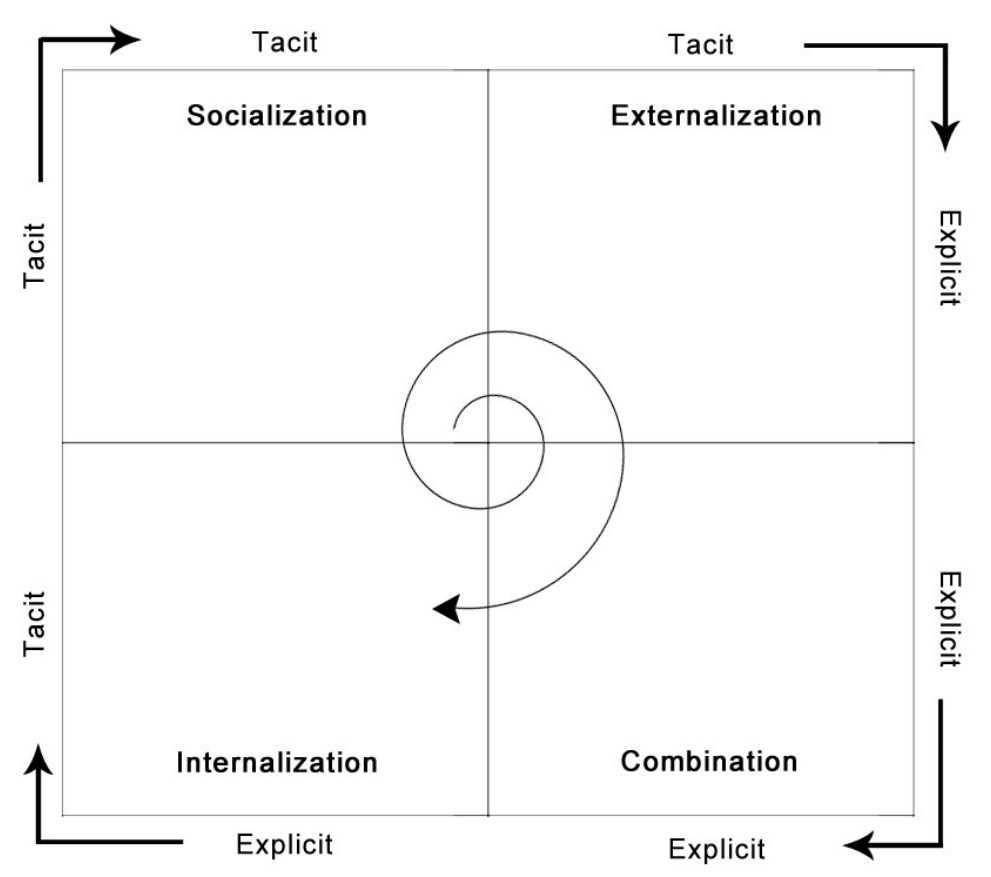

Figure 1. The knowledge spiral [4].

The coexistence of two different forms of knowledge, ascribable, respectively, to information and know-how, even if not explicitly recognized, is well known from centuries and from centuries has become a question discussed in philosophy and other sciences. While newcomers mainly acquire manual skills (from simple handicraft to art) through socialization, going to work in the ateliers and/or workshops of expert people, scientific knowledge and philosophy are, generally, transmitted (let me recall here that transmission happens when the listener re-creates what she has heard) making reference to what is written in books (we do not have space, here, to recall the philosophical question, opened by Plato, of how written texts may contribute to knowledge acquisition or, in other terms, of the role played by his written pages in presenting his theories to his disciples).

With the development of science and technology in the eighteenth and nineteenth centuries, several diverse new professions have emerged, needing a solid know-how, embodying relevant pieces of mathematics and scientific knowledge. For their common features, all these professions were collected under the name of "engineer". Engineering schools invented, for all their courses, a model that characterizes them almost all over the world: Five years of university are divided in two periods: The first one, common to all courses and lasting two years, is dedicated to all the scientific disciplines needed for becoming, later, a professional, while the second, different for each course and lasting three years, is dedicated to get the know-how for exerting a specific profession. Learning mathematics and sciences is propaedeutic to acquiring the know-how for acting as a professional, hypostatizing, in some sense, a segment of Nonaka's knowledge spiral, where internalization precedes socialization. The same model has been adopted in the engineering schools for architecture courses, with the difference that propaedeutic courses, in this case, are dedicated to acquire a solid universal culture, more than to access specialized disciplines. We know that educational programs are under discussion in these years almost at every latitude and longitude. Europe adopted a $3+2$ model (Bologna process; [6]) that was no more based on propaedeutics, but on the bachelor/master distinction: The applications of this model are sharply discussed in many countries. However, in any case, it remains interesting that tacit and explicit knowledge distinction permeates our discourse on knowledge creation and sharing at different levels.

Concluding this resume, it is useful to recall that the issue of how people know has been at the center of attention of philosophers, pedagogues, and psychologists of different schools: The distinction 
between tacit and explicit knowledge, in particular, is of paramount importance for all the scholars that are 'lato sensu' ascribable to the constructivism [7]. Finally, co-creation of knowledge has been brought recently to the attention of the public by the scholars who have developed the concept of 'collective intelligence' [8]: Their starting point is the reformulation of a typical systemic argument, that systems are more than their parts. In this case, what is stressed is that groups and/or communities know more and, therefore, are more intelligent than their individual members. I would like to underline that the idea of multi-disciplinarity is strictly related with collective intelligence, since it assumes that the participation of people with different backgrounds and competencies grants, in facing difficulties and breakdowns, a capability that no single participant can have.

All I have written here refers to contemporary society and to its members, who got their education before the year 2000. However, as many observers have remarked, digital natives, or millennials (these are the two most used names for indicating young people who grew up with digital technologies in their life space) practice in general, and practice knowledge in particular, in a new and diverse mode. Is this changing the picture of knowledge management that I have recalled in these notes? Or, and it may be more interesting, is this showing us something new and diverse about the practice of knowledge, which we did not see before?

This is the reason why I think a good idea, at this moment, to survey what Michel Serres tells us about Thumbelina.

\section{Michel Serres' Thumbelina}

As noted in the Introduction, Michel Serres is a French philosopher, born in 1930, who has frequently taught in the United States, in particular at Stanford University, in the heart of Silicon Valley, California.

He had, therefore, a privileged viewpoint for observing the digital revolution in its making, and he did it with his eyes rich of the wisdom and culture of old Europe. On the one hand, he has not been influenced too much by the emotions provoked by the rapid diffusion of ICT (Information and Communication Technology), avoiding any optimistic or pessimistic attitude; on the other hand, he did not take refuge in scepticism.

He has been able, in this way, to avoid judging which is still an ongoing phenomenon, which is difficult to read, interpret. And to approach it with great caution and openness, with the intention of understanding its character.

His viewpoint is philosophical and anthropological: Philosophical, in the sense that he uses terms knowledge, individual, word, etc., with the rigour of a philosopher, without remaining subject to the distortions they get in the tittle-tattle of media; anthropological, in the sense that he has paid attention to practice and posture of people while interacting with digital devices.

The outcome of these reflections has been published in 2012 in a small, brilliant book entitled "Petite Poucette", translated to English in 2015 with the title "Thumbelina" [1].

Petit Poucette (Thumbelina) is the feminine version for Petit Poucet (Thumbelino). Petit Poucet is the title of a famous fable of Charles Perrault (it appeared in the collection "The Tales of Mother Goose" in 1696; [9]). Thumbelino is also the title of a fable of Grimm brothers, while Thumbelina is the title of a fable of Hans Christian Andersen. In the stories narrated in all these fables, Thumbelino/Thumbelina is a shrewd, autonomous boy/girl who is able to skive off in difficult situations.

Choosing Thumbelina as the lead of his essay, Serres tells us that he looks at the digital revolution from the teenager's viewpoint, that he thinks that, with this respect, girls are more interesting than boys, and finally, he wants to recall us, in a playful way, that teenagers (both males and females) are notable because they digit on their cellular phones with their thumbs.

Thumbelina is, therefore, a teenager, a digital native. What does it mean that she is a digital native, beyond the fact that she is born when personal computers, emails, chats, etc., have been already invented and are widely diffused? In what does she differ from teenagers of previous times, from 
those who have been teenagers twenty, thirty years ago, or more? In what differs from us, the adults of today?

Serres answers to these questions on the basis of what he has discovered, observing her in a tender, curious, and committed way.

The questions he poses are interesting, because they aim to catch what is changing in people's behaviour, in their way of thinking, of relating to each-other, of approaching the world where they live, and the things populating it. They do not demand to discuss, now, how much the digital revolution is really a revolution, nor where it will bring human society, if their outcomes will be positive or negative, which transformations it will provoke, and which perils are opening, and for whom. I do not want to claim that these questions are not interesting, but it seems to me that Serres is telling us that it is impossible to give to them non-trivial answers, if, before, we do not understand, at an anthropological level, what is happening to the people directly using digital devices.

Let us survey, in short, the small book of Serres.

He begins it, by enumerating the differences Thumbelina and her friends exhibit with respect to us, when we were young, and, in some sense, with respect, also, to our adult experience: "Without us even realizing it, a new kind of human being was born in the brief period of time that separates us from the 1970s. He or she no longer has the same body or the same life expectancy. They no longer communicate in the same way; they no longer perceive the same world; they no longer live in the same Nature or inhabit the same space." ([1], p. 7).

Later: "... he or she comprehends differently. [ ... ] He or she writes differently. [ ... ] They no longer speak the same language." ([1], p. 7).

Recalling these transformations, which Serres illustrates with short, incisive, examples, and that would merit a discussion by themselves, we are brought to the first revelation of the book: Millennials have become the first 'individuals': "Until recently, we lived in what we might call our 'belongings': French, Catholics, Jews, Protestants, Muslims, atheists. Southerners or Northerners, females or males, poor or rich ... We belonged to regions and religions, cultures (rural or urban), teams, towns, a sex, a dialect, a party, and a motherland. Through travel, images, the web, and abominable wars, almost all these collectives have been broken apart. Those that remain are unravelling." ([1], p. 9). In this sentence, Serres seems to disregard the belongings of the young people adhering to terrorism and radical ideologies. Without attempting to stand in for him, I can say that Thumbelina has already liberated herself from any belonging generated by ideologies and that the majority of her peers did the same.

At this point, the discourse becomes serious and interesting: As individuals, Thumbelina and her friends experience the death of ideologies, and more, of belongings recruited by those ideologies. ([1], p. 9): "Like an atom without valence, Thumbelina is completely naked. We adults have not invented any new social links" ([1], p. 10).

The birth of the individual represents a deep break in the history of the humanity, to which we did not pay adequate enough attention, that we did not understand in its depth (perhaps because we were thinking that it had already happened), but the novelty of juvenile behaviours and of their way of staying in the world, has there its roots. Thumbelina and her peers are naked and without any defense in face of the world. Families and institutions are no more able neither to protect them, nor to guide their growth, since all previously developed mediators have become ineffective. Additionaly, the world, today, is always more complex and bewildering.

How did digital technology contribute to this outcome? The digital can be considered the third element, after writing and printing, in a sequence of soft but shattering inventions, changing the human condition ([1], p. 26). Serres is quite resolute in claiming that soft revolutions, impacting intelligences, change the world in a deeper way than hard ones, changing production modes, like the bronze and iron ages, the industrial revolution, etc. Digital technology is revolutionary, for its being soft, for its being used by every one in a growing number of everyday situations, impacting the way human beings think, speak, and know, rather than for automation and robots, and their capability 
to change production systems, work and decisional processes: "Though we hardly realize it, we are living together, today, as the children of the book, and the grandchildren of writing." ([1], p. 21).

In conclusion, digital technology has changed and changes our relationships with knowledge, as writing and printing did previously: Identities emerge from aggregations mediated by human knowledge.

Knowledge, up to writing and printing, and also after them, required to human beings an uncritical submission ("A democracy of knowledge has never existed"; ([1], p. 32) that was well represented by the architecture of the lecture room, by the format of the page. In order to access them you had to lie down: Even masters were knowledge servants. Digital technology turns upside down this hierarchy: Knowledge is there, in the net; anyone can access it, selecting what is interesting. No one can impose his/her advantage. "The innovation: the ease of access that has been given to Thumbelina, and to the entire world, their pockets with all the knowledge in their smart phones" ([1], p. 34).

Our world seems unaware of this changes: Lecture rooms are still like they were in the old days, books, even e-books, are made as before, but the authority they exhibit is neutralized; they are no more the privileged places for knowledge transmission. "Thumbelina seeks and finds knowledge in a machine" ([1], p. 37) subverting its specialization, articulation, and organization. The net is a confusing and magic space where things are juxtaposed without any criterion: The net is the supreme place for serendipity, for surprise.

Chaos "occupies the totality of space" ([1], p. 55): We discover, in this way, that the order of knowledge was, truly, the order of its scholars, of the mediators through which we accessed it. Once the mediators disappear, every access to knowledge, every search, creates its order. The chaos that we see is the outcome of the co-existence of several, diverse orders, generated by several diverse accesses, searches, even when they are performed by the same person. This plurality of orders can not be reconciled in a single order and knowledge gets a casual form where dense places are adjacent to patchy places, where information has not a unique sense, where two nearby news items can appear contradictories. "If she consults a good website, Thumbelina [ ... ] can know as much, or more, on a given subject-a decision to be made, public information, the care of oneself-as any teacher, manager, journalist, senior official, CEO, or president, all of whom have reached the pinnacle and are obsessed with glory" ([1], p. 61) but this does not grant to her that what she knows allows her to take the right decision.

The fact that Thumbelina has direct access to knowledge, without overseeing mediators, does neither mean that she is free from conditioning, nor that she is equipped for transforming information into knowledge. Rather, as Serres had already underlined, recalling us that there is no knowledge democracy and that Thumbelina is naked in face of the net, she is unable to filter the contents she finds there, as well as to get them critically. Direct access to knowledge is the novelty in Thumbelina's life, but it should not be considered a good thing 'per se': It is legitimate, in fact, to ask how much Thumbelina is able to know, through it.

We are now ready to approach the problem of how Thumbelina knows.

\section{How Thumbelina Knows}

Michel Serres has indicated to us that Thumbelina, today has a direct access to knowledge, without any mediation, and that this has relevance for all human beings, even for people like me, who are quite older that Thumbelina and who lived in a period of time where the relation with knowledge was strictly mediated by expert people, by professors). This is something radically new, changing forever the way human beings get/create new knowledge.

The very same idea of 'knowledge transmission', on which mankind built its educational organization and its self-awareness, is zeroed in the world of Thumbelina: No one transmits any thing, there is nothing to transmit, recognizing one of the major assumptions of the constructivistic perspective. The partial and incomplete democratization of knowledge, started by the invention of 
writing and extended by that of printing, liberated knowledge from monopolistic control of clergy, without, in any case, eliminating the filter of masters and scholars. A further step is happening today with the Internet: Knowledge mediators are running out. They played a crucial role in the age of script and printing, moving from explaining phenomena (that is something anyone has to do by him/herself) to presenting the scientific theories allowing to explain phenomena. A theory, in fact, is such that any person, when she has learned it, can explain a phenomenon in the same way. Scientific knowledge, even if it depends on masters and scholars, is sharable, reproducible, and falsifiable. For these reasons, we claim that it is half-way democratic.

Schools, universities, and research centers: Human societies have institutions for creating and reproducing knowledge and for disseminating it. The system of sciences has been created in these processes: Scientific disciplines have become always more specialized and structured, so that two different channels have emerged for transmitting them. On the one hand, an elitist and demanding one, for those people who want to become part of the scientific milieu, contributing to the development of scientific knowledge; on the other hand, a universal and widely accessible one, divulgating scientific discoveries and concepts to the large public. This model has never been able to cover in an adequate and complete way the transmission of knowledge between generations: science was too specialized, its vulgate for the large public too simplified, but it worked for two centuries.

Formal education going on in Institutions like schools and universities was not able in any case to cover all forms of knowledge, in particular, it was unable to transmit practical know-how. Therefore, it has been coupled with apprenticeship, the form of knowledge transfer happening between experts and novices when they work together. This is typical in handicraft (but also in art) where novices learn how to do (get their know-how) socializing the tacit knowledge of experts through more or less structured forms of learning by doing.

Apprenticeship allowed novices to gain practical knowledge and this has been recalled when, as recalled in Section 2, in the universities, engineering and architectural schools have developed two original variants of a teaching approach coupling scientific and practical knowledge.

Engineering can be considered a form of meta-knowledge capable of integrating techniques and methods deriving from scientific knowledge in a general approach to problem solving: Technical Universities (Politecnici, in Italian) consider themselves as the depositaries of an original, unitary and successful professional model and of its transmission mode. Architectural schools, on the other hand, combine a first hand knowledge about the human condition and its spatial dimensions with the practice of design, where students learn how to shape the space where human beings live. Architectural design does not want to solve problems, like engineering does; rather, it wants to modify the space (of possible action and interaction) of its inhabitants, opening it at the functional and emotional levels.

In these cases, knowledge is not only transmitted but also re-created by participants practicing and growing their experience. What we have observed in Thumbelina is not, therefore, radically new, it can be considered as a recombination of the different components of previous educational practice. The crisis of the transmission of scientific knowledge [10] provoked by the direct access to knowledge allowed by the digital revolution opens new spaces to other forms of recombining the main ways education is practiced in modern times.

The story we have narrated above, can be rephrased in more abstract terms adopting the terminology Nonaka and co-workers introduced in their studies about the 'knowledge creating' organizations. Let us start from the two forms of knowing, they have brought again to our attention: on the one hand, there is information, stored in digital repositories and represented in texts, diagrams, images or formalized in databases (information is called by Nonaka explicit knowledge, since it can be considered as the extreme form of making knowledge public and scientific knowledge has this form); on the other hand, there is know-how, contained in the heads of human beings and habilitating them to perform effectively (it is called by Nonaka, following Polanyi, tacit knowledge, to underline its private nature). Both, information and know-how, are knowledge and, even if they are not the same knowledge, it is always possible to convert know-how in information and, vice-versa, information in 
know-how: I can transfer to a book, that anyone can read, my tacit knowledge, what I know, modeling it, when needed, through mathematics and scientific theories; I can learn the content of a book reading it, and then become able to use its content in my performances. There is a strict connection between tacit and explicit knowledge, even if they are, irremediably, distinct: Ikujiro Nonaka and Hirotaka Takeuchi, in 'The Knowledge Creating Company' [4], have grounded their knowledge management theory on them.

The kernel of their approach is that knowledge is continuously (re-)created by human beings since knowledge creation is always a transformation of previous knowledge: So when we read a book, we are not receiving the knowledge it contains, rather, we are transforming it into new tacit knowledge; in the same way that things go when we work together with other people, when we write with them or alone. Knowledge creation, claimed Nonaka and Konno [2], in order to be effective, needs to be located in a ' $\mathrm{Ba}^{\prime}$ ', a space for human relationships and interactions. Ba can be physical or digital, or a combination of them: What it important is that its inhabitants recognize it as the place for sharing.

Let us go back, now, to Michel Serres. His Thumbelina has free, immediate and direct, without mediators, access to the knowledge in the web. This is the main effect of the third soft revolution, the digital revolution. How does she move in this new context? If we go close to her, while she browses the web, reads a blog, intervenes in a forum, buys something, participates in a wiki, we will see that she is, as Serres claims, naked in face of the net.

However, she is not intimidated: Whenever she looks for an information, she does not know or she has forgotten-who is the director of that western starring Gregory Peck? Which is the telephone number of Roberto? - she finds it quickly with search engines, encyclopaedias, mail services, etc. This ability to find any type of information, makes her very popular, also, among people of the previous generations, who try to imitate her: Quiz games, claims like "I have it on the tip of my tongue", are no more frightening to anyone. Additionally, when she wants to form an opinion on a general interest question-Are you in favour of drills? Are you for or against gay marriages?-Thumbelina is autonomous and searches by herself for the information, allowing her to take a position. It is not like for her parents, who, often, adopted confidently the opinion coherent with the ideology of their reference community (being not relevant if it was religious, political or professional). She decides freely choosing the argumentation convincing her.

In any case, these are relatively simple cases, turning out in the moment when she finds the information she is looking for: Considering them situations involving knowledge and knowing seems to me excessive, since no real knowledge is transformed or generated.

However, when Thumbelina's search is less episodic, when it is serving within an activity, a performance, engaging her with other people, when it is embedded in a story of actions and interactions, in a compulsory context of references, then that search becomes part of a knowledge creation process. As an example, you can consider a group of makers, who are willing to build a new thing with new interaction capabilities: Any active participant browses the net to get what is needed (in terms of knowledge) in order to bring their project to completion, and, doing so, she internalizes new knowledge, that is immediately shared, and checked by other participants with respect to the ongoing project. In these cases, access to knowledge reiterates and elongates in time widening accessed explicit knowledge and, progressively, the (tacit) knowledge, Thumbelina and her friends create and share, grows: What they share makes them a team, united by the experience they live together, even when, at the beginning, they had diverse cultural and disciplinary backgrounds. Thumbelina and friends learn how to perform, become capable to face breakdowns and improve their capability to justify and explain what they do and how they do it: Their knowledge, while it habilitates them to do, becomes the basis of their responsibility (etymologically: Of their 'ability to respond'). Thumbelina's accesses to the net intertwine with her interactions with her friends: Thumbelina is not alone. In conclusion, let me say add the amalgam of cultural tools, artefacts and symbol systems constituting the explicit knowledge Thumbelina and her friends use in this endeavour can be analyzed and understood through the lens of Distributed Cognition [11]. 
Thumbelina is still naked, without mediators guiding her navigation, but she is not alone, because she is in a collective, with her friends, with whom she makes decisions, and performs. She discusses the information (explicit knowledge) she finds in the web with her team, creating together with its members new knowledge, growing their awareness and determinacy. Without also looking closer at this process of sharing and remixing, giving rise to a shared evolving knowledge, it is not possible to understand the relationship between Thumbelina and knowledge. Makers and digital handicraftsmen who use 3D printers, connect, through Arduino, their outcomes with sensors and engines, building in short amounts of time the prototypes of new things; young people who launch start-ups, presenting to the public and/or putting in the market their innovation, despite their inexperience: What unites all of them, is that they are not alone, that together they become strong and effective.

I do not want, with the above claims, to sing an uncritical paean to the millennials who create the future in the net: I know that, often, what they do does not merit attention, does not find users, and does not find customers. I find interesting that their way of accessing the information in the web as a collective allows them to transform that information into knowledge. Their social network pulsates (intertwining enlargements and contractions), without declining: The team/community giving to each one of them the capacity to get/create new knowledge always becomes more effective.

It is in fact, this collective, with the variable geometry of its interactions (where different groups of participants, from the full collective to any of its subsets, interact [12]), who plays the role of mediator between Thumbelina's team and explicit knowledge.

Thumbelina is, therefore, naked, because she has no trusted mediators, but is not alone (because she lives her experiences together with larger or smaller groups of friends, peers, and partners) in front of knowledge. The collective she is member of constitutes the filter through which the information of the web becomes knowledge: The conceptual categories introduced by Nonaka and Takeuchi (see previous section) can help us to understand how this happens.

As anticipated in the previous section, in fact, in "The Knowledge Creating Company", Nonaka and Takeuchi affirm that knowledge cannot be transmitted between people, rather, it can only be re-created by the person who listens to what another person says, or reads what is written in a text in accordance with a <stimulus-response > mechanism. Internalization (from explicit to tacit), externalization (from tacit to explicit), socialization (from tacit to tacit) and combination (from explicit to explicit) are the four types of knowledge transformations, and they can be useful to better understand the access to digital information: The members of a collective transform the information they find in the net into (tacit) knowledge, without the help of any expert mediator validating the process, through their internalizations, externalizations, socializations, and combinations.

We can assume that Thumbelina obtains, collaborating with her collective (with the team whose she is part of)—confronting different sources, conversing, disputing—what people once could get reading books, listening to professors, telling them what they understood, and getting further explanations of what they did not understand. It cannot be disputed that interacting with other people has limits as a mediator: It works well in aiding Thumbelina in socialization, but it may be un-effective, for example, when she needs to internalize highly specialized and abstract (explicit) knowledge (Sebastiano Bagnara and colleagues discuss this issue [13,14]). Another example: If she needs to use a new material, it is necessary that within the collective there is someone who knows how to do with it: handicraft knowledge, that probably is the most relevant expression of 'know-how', grows within human experience, it is not created ex novo, from scratch. The reference for handicraft is always apprenticeship, where youngsters socialize with expert people. Continuing with the examples: If she needs to access scientific knowledge, that is based on, and is derived from, formal theories, expressed in mathematical terms, it is necessary that someone who has studied those theories and possesses them (applying scientific knowledge is uncertain and risky, if you do not master reference theories). As a conclusion, if the collective, which Thumbelina is part of, does not include experts of the specialized knowledge needed to do what was planned, then she will find serious difficulties in getting and creating new knowledge, risking remaining entangled in the narrow space of badly 
possessed and inaccurate knowledge. The caveat of Roberto Casati [15] against Digital Colonialism applies well in these situations. I underline this fact, because, as Serres recalls to us, Thumbelina and her peers, as digital natives, live in a world where traditional forms of knowledge transmission (lecture, text-book) are becoming always less effective (and less frequented) and new forms that are capable of substituting them, have not yet been invented.

As a matter of fact, the acquisition of high, scientific knowledge is problematic without the presence of an expert teacher, and this situation threatens Thumbelina, because, as Serres has observed, even in the net, scientific knowledge has its traditional forms (on the one side, specialized text-books, on the other, popular over-simplifications). In the attempt to conform to moving forward novelties without questioning their identities, cultural and scientific institutions and the people who guide and populate them did some reforms that are no more than a plaster cast on wooden legs, a patching up ([1], p. 13). Yet "we all sense that we urgently need a decisive change in teaching" ([1], p.13); "The page-format so dominates us - though we are hardly aware of it - that even our new technologies have not been able to break away from it" ([1], p. 23). The same happens in the buildings where knowledge is made accessible, in university departments: "the same layout of the floors, the same classrooms, the same hallways" ([1], p. 23) and Serres concludes: "as if the recent revolution, at least as powerful as those of the printing press and writing, had changed nothing in our knowledge, in our pedagogy, or in the space of the university itself, which was invented long ago by and for the book" ([1], p. 23). We can still analyze how Thumbelina knows using the four knowledge transformation modes by Nonaka, but we cannot imagine that putting them in a sequence, like the knowledge spiral does, can capture the behaviour of Thumbelina. For her, definitively, the four transformation modes are simultaneous; they are activated and ordered by the practice engaging her in a way that does not follow any rule or principle. Therefore, books and lectures always lose their effectiveness, and other ways of making knowledge explicit must be invented and experimented on in order to be capable of better intertwining with the other forms of knowledge creation.

If we want to avoid a dramatic impoverishment of the capability of learning by young people, then, we need to rethink the way networked knowledge is organized, beginning with the practice of its acquisition and renovation. It is a broad terrain of research and experimentation and beginning to work on it is urgent.

We are not at the zero point in this endeavour, because there are several ideas and research that can be good starting points. First, systems supporting the collaborative annotation of documents (e.g., [16]) can be adopted, so that any document becomes a dynamic support for the conversations users have about it, and a permanent trace of the new knowledge created during its reading within the collective; second, we can use the cartography of controversies that Bruno Latour and his collaborators are developing at the theoretical [17] and applicative [18] levels. Knowledge, in fact, is not centered on facts, as believing that there is a uniform and consistent knowledge basis lets us suppose. Efforts for developing a semantic web [19] in its radical formulation, for example, suffer for this misleading idea. On the contrary, Latour [17] suggests us that knowledge aggregates around discussions and controversies. Organizing information around the questions it illustrates, allows the creation of an effective support to the knowledge each of us continuously re-creates, in a dialogic process, uniting and differentiating all the people sharing it; finally, it is important to take into account that the interactions (conversations) through which people create and share knowledge are part of stories involving varying groups of people, who, in their Ba [2], share in different moments and at different levels that knowledge. I have designed, with a group of young collaborators, itsme, a prototype of a new front-end for the operating systems of personal computers [20], for supporting these stories. Itsme abandons the well-known desktop metaphor [21] that shapes all personal computers after the Macintosh, for grounding its interface on a new metaphor, we have called 'stories and venues': In accordance with this, itsme creates a virtual place (venue) for each story lived by its user. In each venue, the user can find the traces of all the actions and interaction she did during the related story, as well as all the people with whom they interact and the means for any new interactions between 
them. To avoid any rigidity, itsme also supports, in a transparent way, the creation, splitting, and merging of venues, so that users can always rearrange the digital extension of their place in accordance with their ideas and wills, and, to avoid problems with high critical mass thresholds, it does not require that other people adopt it, to deliver its services to its users.

At a different level, what we have learned from Thumbelina opens, I think, a reflection on the role of teaching. Even one who is inclined to see in her behaviour only positive aspects, cannot neglect, in fact, that there are forms of knowledge that are quite difficult to learn, without the help of experts who practice them at the research level and who have a good experience of how they can be taught, learned and applied. As we have recalled in previous sections, we do not need to invent anything: Engineering and, mainly, architecture indicate to us the direction along which we can move. Passing from transmission to the co-creation model requires that professors and scholars rethink their positions in the learning process, stepping down from their chair to merge with Thumbelina and her peers while they are sharing their knowledge experience. Teachers must interact with their students so that they understand what they can and cannot do, limiting their lectures to the exposition of the most difficult and complex parts of their discipline. In my course of 'Interaction Design Laboratory' at the University of Milano, Bicocca, I have been experimenting on, for several years, forms of participative teaching with promising results.

The role, sketched above, teachers have and should have in the world of Thumbelina, suggests me to conclude this section with specific attention to the development of sciences and humanistic disciplines. It is clear, in fact, that educating researchers, a practice that has remained almost unchanged, even in these recent years, is a different problem with respect to educating millennials, who practice, as we have seen above, direct access to knowledge on the net. If we look closer at the education of students aiming to become researchers, we can see that acquiring specialized and theoretic knowledge, when it is coupled with experimental verifications, is based on a dialogue within which knowledge is continuously recreated and re-defined, discussing theories with respect to experiments, so that, even in this case, learning requires internalization. In addition, scientific learning can find an effective support in the net and, conversely, is enriched by the teacher stepping down to interact with the students, who learn and do experiments together. The difference between educating researchers and educating millennials, who do not have ambitions to dedicate themselves to science, lies in the theme they work on: On the one hand, scientific theories themselves, on the other hand, their support for creating or adapting new or existing technologies in their experiences. We can say, therefore, that education should always be a collaborative practice between teachers and pupils, where the focus should be on learning rather than on teaching. It remains that, while books and lectures play a crucial role (internalization) in becoming an expert scholar of a scientific discipline, the net and group interactions (socialization) are prevailing when science is only a means. It is the responsibility of the teacher to choose the best mix of directly presented and recalled, making reference to books and/or other written material and content, and to couple it with conversations with the students.

\section{Conclusions}

In the previous pages of this text, I have tried to show that the chaos, the noise ("the noise occupies the totality of space"; ([1], p. 55), is really constituted by the coexistence of several, diverse, continuously-changing, orders (voices). These orders are continuously re-defined and re-arranged within the experiences of the users on the net, remaining always incomplete and contradictory, but any new breakdown, opening new ambiguities and contradictions, is compensated for by partial and local re-alignments. Mis-alignments and re-alignments characterize, altogether, any new access to explicit knowledge, any new sharing of it within a collective.

It is a mistake to consider the incompleteness and inconsistency that we see in the knowledge shared within a collective, as being due to the limited level of sharing reached by its members to their partial rationality; rather, it is intrinsic to the dynamics of knowledge-sharing within the collective, where it uninterruptedly aligns the previous knowledge of its members and innovates it, breaking 
its integrity. Using a mathematical metaphor, we can say that the chaos evoked by Serres is a system of manifold semi-orders, each one asymptotically tending to completeness and consistency, without ever reaching them. However, each semi-order, even if it tends to become a full order, remains isolated by the other semi-orders, and from this is derived the chaos. All these orders, as a matter of fact, are independent from each other and it is not possible to put them into a hierarchy so that they are brought again into a unique structured order.

Does this mean that chaos filling all our space is fated to create a fog, becoming always more thick and unpierceable? That the dream of a shared knowledge is a chimera? No, because we can see that, at a different level and in indirect forms, the conversations of the members of the collective, marrying aligning and mis-aligning, innovation and sharing, can be considered the ordering mechanisms of shared knowledge: In fact, they are both increasing the degree of knowledge sharing within the collective and indicating to its members that new knowledge has been created. At a higher level, the shortcuts among the diverse experiences of human beings, their common participation in institutional processes like schools and universities, their use of social computing platforms, their access to the same, immense, unique repository of documents and data that is the web, create the conditions for an asymptotic alignment of their knowledge.

The new order that is emerging, after the third soft revolution (the digital revolution) recalled by Serres, is an order of stories and changes, rather than an order of facts and data: It is a dynamic order of knowledge creation, not of knowledge items. We will learn to live with it, to manage it, observing carefully how people behave in these times, beginning, for registry and anthropological reasons, with Thumbelina and her peers, and inventing systems, aiming not to neutralize the chaos around us, but to make visible and understandable the orders constituting it. The asymptotical convergence of what individuals know, in fact, has nothing to do with magic: The conversations among the members of collectives (groups and/or communities) are both the mediating and the sharing mechanism, granting that each participant creates new knowledge and aligns it to what other know. Individual knowledge creation is only possible within collective knowledge creation.

The discourse, now, stops here. Thumbelina has helped us to explore the changing world we are experiencing, without understanding it, and to appreciate how she and her friends and peers try to give sense to their actions and interactions. It is up to us to help her, giving her the tools and means for doing it without encountering too many obstacles.

Acknowledgments: I do not personally know Michel Serres, but my first acknowledgement goes to him: Reading his book has been for me source of intellectual pleasure and inspiration, because it has offered to me an extraordinary starting point for what I have presented in three pages. From years, I worked on the boundaries separating and connecting technology and human beings; meeting there Thumbelina, it was natural, for me, to adopt her as my guide. It has been natural, for my different disciplinary competencies (I am a computer scientist working on people-centred and interaction design), to move further in the field of technology and, for my being an innovation designer, to imagine how the boundaries between technology and people could be moved with respect those existing now. This text contains this attempt, for which I pay, again, a tribute to Michel Serres, even if I am the only responsible of what it contains. My friends and colleagues with whom, in Milano and around the world, we try to develop the perspective of 'socially embedded technologies', have discussed with me many of the issues recalled in this paper. I am grateful for this to them. Finally, Alessandra Agostini, Alessio Bellino, Sebastiano Bagnara, Federico Butera, Alessandro Ghisalberti, Remo Pareschi, Piero Rivizzigno and Carla Simone read and commented on a preliminary version of this text, discussing it with me and indicating me the stylistic, argumentative and contextual changes they considered useful. Their advice has been very useful, and therefore I thank them. Finally I must thank the three anonymous reviewers who read my preliminary text. I rarely had so careful, open and rigorous readers of my work. Their comments were of paramount importance for improving this paper.

Conflicts of Interest: The author declares no conflicts of interest.

\section{References}

1. Serres, M. Thumbelina. The Culture and Technology of Millennials; Rowman \& Littlefield: Lanham, MA, USA, 2015. 
2. Nonaka, I.; Konno, N. The Concept of "Ba": Building a foundation for knowledge creation. Calif. Manag. Rev. 1998, 40, 40-54. [CrossRef]

3. Nonaka, I.; von Krogh, G.; Voelpel, S. Organizational Knowledge Creation Theory: Evolutionary Paths and Future Advances. Organ. Stud. 2006, 27, 1179-1208. [CrossRef]

4. Nonaka, I.; Takeuchi, H. The Knowledge Creating Company; Oxford University Press: Oxford, UK, 1995.

5. Polanyi, M. The Tacit Dimension; The University of Chicago Press: Chicago, IL, USA, 2009.

6. Neave, G. The Bologna Declaration: Some of the Historic Dilemmas Posed by the Reconstruction of the Community in Europe's Systems of Higher Education. Educ. Policy 2003, 17, 141-164. [CrossRef]

7. Von Glaserfeld, E. Radical Constructivism: A Way of Knowing and Learning; The Falmer Press: London, UK, 1995.

8. Lévy, P. Collective Intelligence: Mankind's Emerging World in Cyberspace; Perseus Books: Cambrigde, MA, USA, 1997.

9. Perrault, C. The Tales of Mother Goose; Sleeping Cat Books: Kent, OH, USA, 2014. (In Bilingual)

10. Barnes, B. Scientific Knowledge and Sociological Theories; Routledge \& Kegan Paul: London, UK, 2013.

11. Sutton, J. Distributed cognition: Domains and dimensions. Pragmat. Cognit. 2006, 14, 235-247.

12. De Michelis, G. La geometria variabile dell'Intelligenza Collettiva. Sist. Intell. 2014, 26, 521-532. (In Italian)

13. Bagnara, S.; Pozzi, S. Apprendere il saper fare. In Artigianato Design Innovazione; Tosi, F., Lotti, G., Follesa, S., Rinaldi, A., Eds.; DIDA: Firenze, Italy, 2016; pp. 28-37. (In Italian)

14. Bagnara, S.; Marti, P.; Pozzi, S. Le dimensioni sociali del design. Sist. Intell. 2015, 27, 127-140. (In Italian)

15. Casati, R. Contro il Colonialismo Digitale (Against Digital Colonialism); Editori Laterza: Bari, Italy, 2013. (In Italian)

16. Cabitza, F.; Simone, C.; Locatelli, M.P. Supporting artifact-mediated discourses through a recursive annotation tool. In Proceedings of the 17th ACM International conference on Supporting Group Work, Sanibel Island, FL, USA, 27-31 October 2012; pp. 253-262.

17. Latour, B. Enquéte Sur les Modes d'Existence; La Decouverte: Paris, France, 2012. (In French)

18. Venturini, T. Building on faults. Public Underst. Sci. 2012, 21, 796-812. [CrossRef] [PubMed]

19. Berners Lee, T. The Semantic Web. Sci. Am. 2001, 284, 34-43. [CrossRef]

20. De Michelis, G. Interaction design at itsme. Sistemi Intelligenti. In Designing Socially Embedded Technologies in the Real World; Wulf, V., Schmidt, K., Randall, D., Eds.; Springer: Berlin, Germany, 2015; pp. 158-173.

21. Kay, A. Microelectronics and the personal computer. Sci. Am. 1977, 237, 230-244. [CrossRef] 